\title{
Nationwide survey of pediatric intracranial arteriovenous shunts in Japan: Japanese Pediatric Arteriovenous Shunts Study (JPAS)
}

\author{
Aiko Terada, MD, ${ }^{1,2}$ Masaki Komiyama, MD, ${ }^{2}$ Tomoya Ishiguro, MD, ${ }^{2}$ Yasunari Niimi, MD, $\mathrm{PhD},{ }^{3}$ and \\ Hidenori Oishi, MD, PhD ${ }^{4,5}$

\begin{abstract}
Departments of ${ }^{1}$ Neurosurgery and ${ }^{2}$ Neurointervention, Osaka City General Hospital, Osaka; ${ }^{3}$ Department of Neuroendovascular Therapy, St. Luke's International Hospital, Tokyo; and Departments of ${ }^{4}$ Neuroendovascular Therapy and ${ }^{5}$ Neurosurgery,
\end{abstract} \\ Juntendo University Faculty of Medicine, Tokyo, Japan
}

OBJECTIVE This nationwide study was organized to evaluate the clinical characteristics, especially the annual detected rate, of pediatric intracranial arteriovenous (AV) shunts such as brain AV malformations (BAVMs), pial AV fistulas (PAVFs), vein of Galen aneurysmal malformations (VGAMs), and dural AV fistulas (DAVFs) in Japan.

METHODS Participation invitation emails for the study were sent to all members of the Japanese Society for Neuroendovascular Therapy and the Japanese Society for Pediatric Neurosurgery, totaling 4123 physicians. Excel files were attached to the emails to collect clinical data on patients aged 5 years old or younger with intracranial AV shunts at each hospital in the 5-year period from 2012 to 2016.

RESULTS Representative physicians from 209 hospitals returned Excel files containing the patient data. Thirty-four hospitals reported on 72 patients with intracranial AV shunts. Among this cohort, 24 patients (33\%) had BAVMs, 22 (31\%) had PAVFs, $16(22 \%)$ had VGAMs, and $10(14 \%)$ had DAVFs. Male predominance (70\%) was observed among all types of AV shunts. Most PAVFs (73\%), VGAMs (88\%), and DAVFs (100\%) were diagnosed in patients younger than 1 year, especially neonates, whereas most BAVMs $(92 \%)$ were diagnosed in children older than 1 year. In the patients older than 1 year, BAVMs were relatively common, and VGAMs and DAVFs were rare.

CONCLUSIONS The annual detected rates of BAVMs, PAVFs, VGAMs, and DAVFs in patients 5 years old or younger were $0.0775,0.0710,0.0517$, and 0.0323 per 100,000 persons, respectively. In neonates and infants, VGAM, DAVF, and PAVF were relatively common, but BAVMs were extremely rare.

https://thejns.org/doi/abs/10.3171/2018.5.PEDS18123

KEYWORDS brain arteriovenous shunt; incidence; Japanese population; pediatric vascular disease; vascular disorders

$\mathrm{P}$ EDIATRIC intracranial arteriovenous (AV) shunts include brain AV malformations (BAVMs) with nidus, pial AV fistulas (PAVFs), vein of Galen aneurysmal malformations (VGAMs), and dural AV fistulas (DAVFs). ${ }^{22}$ Because pediatric intracranial AV shunts have been predominately reported from tertiary care medical centers, it is difficult to know the actual incidence of these lesions. "Annual detected rates" (ADRs) rather than "incidences" are used in this paper to define the actual detected number of new patients with each disease per year. ${ }^{3}$
Brain AVM with nidus was believed to be a congenital vascular abnormality, meaning that abnormal embryonic vascular structures formed in utero remain after birth and become symptomatic later in life. ${ }^{10,19}$ However, recent studies have suggested that most BAVMs do not exist at birth and are formed de novo in the postnatal period. These conclusions were based on the facts that very few patients have symptomatic BAVMs in early childhood ${ }^{12,15}$ and that most BAVMs become symptomatic in patients older than 30 years of age. ${ }^{1,20,24}$ Pial AVF was also believed to a con-

ABBREVIATIONS ADR = annual detected rate; $A \mathrm{~V}=$ arteriovenous; $\mathrm{BAOS}=$ Bicêrtre Admission and Outcome Score; $\mathrm{BAVM}=$ brain $\mathrm{AV}$ malformation; $\mathrm{BNES}=\mathrm{Bicêrtre}$ Neonatal Evaluation Score; DAVF = dural AV fistula; JPAS = Japanese Pediatric Arteriovenous Shunts Study; PAVF = pial AV fistula; TAE = transarterial embolization; TVE = transvenous embolization; VGAM = vein of Galen aneurysmal malformation.

SUBMITTED February 22, 2018. ACCEPTED May 10, 2018.

INCLUDE WHEN CITING Published online July 27, 2018; DOI: 10.3171/2018.5.PEDS18123. 
TABLE 1. Bicêrtre Neonatal Evaluation Scores

\begin{tabular}{|c|c|c|c|c|c|}
\hline Points & Cardiac Function & Cerebral Function & Respiratory Function & Hepatic Function & Renal Function \\
\hline 5 & Normal & Normal & Normal & - & - \\
\hline 4 & $\begin{array}{l}\text { Overload, no medical } \\
\text { treatment }\end{array}$ & $\begin{array}{l}\text { Subclinical, isolated EEG } \\
\text { abnormalities }\end{array}$ & Tachypnea, finishes bottle & - & - \\
\hline 3 & $\begin{array}{l}\text { Failure; stable with } \\
\text { medical treatment }\end{array}$ & $\begin{array}{l}\text { Nonconvulsive intermittent } \\
\text { neurologic signs }\end{array}$ & $\begin{array}{l}\text { Tachypnea, does not finish } \\
\text { bottle }\end{array}$ & $\begin{array}{l}\text { No hepatomegaly, normal } \\
\text { hepatic function }\end{array}$ & Normal \\
\hline 2 & $\begin{array}{c}\text { Failure; not stable with } \\
\text { medical treatment }\end{array}$ & Isolated convulsion & $\begin{array}{c}\text { Assisted ventilation, normal } \\
\text { saturation } \mathrm{FIO}_{2}<25 \%\end{array}$ & $\begin{array}{l}\text { Hepatomegaly, normal } \\
\text { hepatic function }\end{array}$ & Transient anuria \\
\hline 1 & Ventilation necessary & Seizures & $\begin{array}{l}\text { Assisted ventilation, normal } \\
\text { saturation } \mathrm{FIO}_{2}>25 \%\end{array}$ & $\begin{array}{l}\text { Moderate or transient } \\
\text { hepatic insufficiency }\end{array}$ & $\begin{array}{r}\text { Unstable diuresis } \\
\text { with treatment }\end{array}$ \\
\hline 0 & $\begin{array}{l}\text { Resistant to medical } \\
\text { therapy }\end{array}$ & $\begin{array}{l}\text { Permanent neurological } \\
\text { signs }\end{array}$ & $\begin{array}{l}\text { Assisted ventilation, desatu- } \\
\text { ration }\end{array}$ & $\begin{array}{l}\text { Abnormal coagulation, } \\
\text { elevated enzymes }\end{array}$ & Anuria \\
\hline
\end{tabular}

$\mathrm{EEG}=$ electroencephalogram; $\mathrm{FIO}_{2}=$ fractional inspired oxygen .

Higher score means better clinical status. Maximal score $=5$ (cardiac) +5 (cerebral) +5 (respiratory) +3 (hepatic) $+3($ renal $)=21$

Reproduced from Lasjaunias et al., The management of vein of Galen aneurysmal malformations, Neurosurgery, 2006, 59, 5 Suppl 3, S184-S194, by permission of

Oxford University Press on behalf of the Congress of Neurological Surgeons.

genital abnormality typically becoming symptomatic after infancy, 7,25 but it has also been observed in utero and in the neonatal period. The different ADRs of intracranial AV shunts by age (antenatal, neonatal, infantile, and childhood) may provide insight into when these vascular abnormalities are formed. To our knowledge, no population-based study of pediatric AV shunt ADRs has been reported. Therefore, we organized a nationwide survey, the Japanese Pediatric Arteriovenous Shunts Study (JPAS), to define clinical characteristics, especially ADRs, of pediatric intracranial AV shunts in Japan.

\section{Methods}

The JPAS was approved by the Institutional Review Board of Osaka City General Hospital. The approvals of the institutional review boards of the individual hospitals surveyed were not required. Emails requesting participation in this study were delivered to all 3555 members of the Japanese Society for Neuroendovascular Therapy in May 2017 and all 568 members of the Japanese Society for Pediatric Neurosurgery in June 2017, totaling 4123 physicians. Emails were not directly delivered to any hospitals. Representative physicians of each hospital were asked to respond to one of the authors (M.K.) by the end of $\mathrm{Au}-$ gust 2017. Although the methods of data collection at each hospital were not defined, representative physicians were asked to report their hospital's data. Email queries enabled direct access to all physicians who might be responsible for the treatment of pediatric patients with intracranial AV shunts. In early September, emails were redelivered to physicians in selected hospitals that were expected to have such pediatric patients and had not responded. Data collection was extended one month until the end of September 2017 to increase participation.

Inclusion criteria for the study were patients with newly diagnosed intracranial AV shunts and an age of 5 years or younger during the 5-year period between January 1 , 2012, and December 31, 2016. Intracranial AV shunts were classified as BAVMs, PAVFs, VGAMs, or DAVFs. ${ }^{22} \mathrm{~Pa}-$ tients were also stratified into three age groups: neonates (within 28 days after birth), infants 1 year old or younger, and children 5 years old or younger. Stillborn children, if any, were reported separately.

Acquired clinical data were as follows: age at initial diagnosis, birth date (year and month), gestation period, sex, birth weight, Apgar scores at 1 and 5 minutes, diagnosis (BAVM, PAVF, VGAM-choroidal type, VGAM-mural type, VGAM-mixed type, DAVF, others), lesion location (supratentorial, infratentorial, galenic cistern, torcular, others), symptoms and signs (heart failure, respiratory failure, fetal hydrops, consciousness disturbance, developmental delay, seizure, hemiparesis, others), CT and/ or MRI findings (hemorrhage, infarction, hydrocephalus, brain atrophy, others), Bicêrtre Neonatal Evaluation Scores (BNESs; Table 1) for neonates, ${ }^{17}$ pretreatment status according to Bicêrtre Admission and Outcome Scores (BAOSs; Table 2) ${ }^{17}$ except for neonates, referral pattern, treatment (medical, endovascular, surgical, irradiation, cerebrospinal fluid shunt, others), number of transarterial embolizations (TAEs) and transvenous embolization (TVE), outcome according to BAOS, and follow-up periods (months). These items were filled out if applicable. In this report, BAOSs 1-2 and 3-5 for outcome estimation were defined as unfavorable and favorable, respectively. ${ }^{2}$

\section{Statistical Analysis}

Populations of persons 5 years old or younger in the years from 2012 to 2016 in Japan were reported as $6,342,000 ; 6,312,000 ; 6,258,000 ; 6,054,000 ; 6,009,000$, respectively, from the Statistics Bureau of the Ministry of Internal Affairs and Communications (https://www.e-stat. go.jp). Thus, the total population of persons 5 years or younger for those 5 years was $30,975,000$. We used these data to calculate the ADRs of the diseases in this report.

Statistical analyses were performed using the R statistical package (version 3.4.2, The R Foundation for Statistical Computing, http://www.R-project.org). Spearman's rank correlation coefficients were calculated between pretreatment status in terms of BNES, birth weight, gestation 
TABLE 2. Bicêrtre Admission and Outcome Scores

\begin{tabular}{cl}
\hline Score & \multicolumn{1}{c}{ Condition } \\
\hline 5 & Normal (N) \\
\hline 4 & $\begin{array}{c}\text { Minimal nonneurological symptoms, not treated (MS), and/or } \\
\text { asymptomatic enlargement of the cardiac silhouette }\end{array}$ \\
\hline 3 & $\begin{array}{c}\text { Transient neurological symptoms, not treated (TNS), and/or } \\
\text { asymptomatic cardiac overload under treatment }\end{array}$ \\
\hline 2 & $\begin{array}{c}\text { Permanent minor neurological symptoms, mental retarda- } \\
\text { tion of up to 20\%, nonpermanent neurological symptoms } \\
\text { under treatment (MNS), normal school with support, and/ } \\
\text { or cardiac failure stabilized with treatment }\end{array}$ \\
& $\begin{array}{c}\text { Severe neurological symptoms, mental retardation of more } \\
\text { than 20\% (SNS), specialized school and/or cardiac failure } \\
\text { unstable despite treatment }\end{array}$ \\
\hline 0 & Death (D) \\
\hline
\end{tabular}

This score is not applied to neonates. Higher score means better clinical status. In this report, BAOSs $1-2$ and 3-5 in the assessment of outcome are defined as unfavorable and favorable, respectively.

Reproduced from Lasjaunias et al., The management of vein of Galen aneurysmal malformations, Neurosurgery, 2006, 59, 5 Suppl 3, S184-S194, by permission of Oxford University Press on behalf of the Congress of Neurological Surgeons.

period, and Apgar scores for neonates or BAOS at diagnosis for infants and children, and posttreatment BAOS. Statistically, $\mathrm{p}$ values $<0.05$ were considered significant. Ninety-five percent confidence intervals of the ADRs of the intracranial AV shunts were calculated using the tails of Poisson distribution.

\section{Results \\ Hospital Participation}

Representative physicians from 209 hospitals returned by email the Excel files containing patient data from their hospital. If we assume that at least one of the physicians who received the invitation mails belongs to each university hospital or children's hospital, $54(68 \%)$ of 79 university hospitals and 25 (69\%) of 36 children's hospitals returned patient data. If a medical university had several affiliated hospitals, the number of hospitals was counted as 1 . It is implied that most hospitals that did not participate in this study were hospitals for adults without pediatric facilities or were children's hospitals without neurosurgical departments. Many university hospitals in Japan cannot treat pediatric intracranial AV shunts. Furthermore, most children's hospitals have no in-house neurointerventionalist for endovascular treatment. Therefore, the 209 participating hospitals comprised almost all of the major general or neurosurgical hospitals and children's hospitals in Japan that treat pediatric intracranial AV shunts. One hundred seventy-four hospitals $(83.3 \%)$ had no patients with intracranial AV shunts. Eighty-eight pediatric patients from the remaining 35 hospitals were enrolled in the study; however, 12 patients were excluded because they had been diagnosed prior to the study period. Dual enrollment was checked by the patient's disease, birth date (year and month), other clinical data, and hospital location. Four patients' data from two hospitals were unified because of dual enrollments; thus, dual enrollments were strictly avoided. Ultimately, 72 patients reported from 34 hospitals were included and analyzed in this report.

\section{Geographic Distribution in Japan}

A total of 34 responding hospitals had at least one patient with an intracranial AV shunt and a mean of 2.2 patients. The geographic distribution of the hospitals where these patients were ultimately treated was plotted on a map of Japan (Fig. 1). Two hospitals were not plotted since they contributed only to diagnosis. A maximum of 18 patients were treated in a single hospital. The 32 hospitals were distributed in 19 of 47 prefectures in Japan. The 72 patients were relatively concentrated in western and eastern urban areas: 18 patients were treated in 1 hospital in Osaka, and 18 were treated in 7 hospitals in Tokyo. Most patients were referred to these major hospitals from their local hospitals.

\section{ADRs of Intracranial AV Shunts}

In the 5-year study period, there were 72 patients with intracranial AV shunts: 24 (33\%) with BAVMs, 22 (31\%) with PAVFs, 16 (22\%) with VGAMs, and 10 (14\%) with DAVFs (Table 3). The diagnosis for each patient was selected by the reporting physician from a pop-up menu of these diseases in the Excel file. The annual number of patients with intracranial AV shunts who were 5 years old or younger in Japan was calculated to be 14 in total, including 5 patients with BAVMs, 4 with PAVFs, 3 with VGAMs, and 2 with DAVFs. The mean annual population of those 5 years old or younger in Japan was 6,195,000, or approximately 6.2 million people.

The ADR of brain AV shunts was 0.232 per 100,000 persons aged 5 years or younger (95\% CI 0.182-0.293). The ADRs of BAVM, PAVF, VGAM, and DAVF were 0.0775 (95\% CI 0.0496-0.115), 0.0710 (95\% CI 0.0445$0.108), 0.0517$ (95\% CI 0.0295-0.0839), and 0.0323 (95\% CI $0.0155-0.0594)$ per 100,000 persons aged 5 years or younger, respectively.

In the neonatal and infantile periods (age $<1$ year old), PAVFs, VGAMs, and DAVFs were relatively common, but BAVMs were rare. In this age group, 15 patients with PAVFs, 14 with VGAMs, 9 with DAVFs, and 2 with BAVMs were reported, excluding the patients who had died in utero. After the age of 1 year, BAVMs became more common, and VGAMs and DAVFs were less common. Male predominance was noted overall (70\%) and in each type of intracranial AV shunt. Excluding the 2 fetal deaths, 3 patients with VGAMs died among a total of 70 patients who were born alive, indicating a mortality rate of $4.3 \%$ for pediatric intracranial AV shunts in this study.

\section{BAVMs}

Twenty-two BAVMs were diagnosed in children, whereas only one BAVM each was diagnosed in a neonate and an infant (Table 4). In all age groups, males were dominant (63\%). Lesions were supratentorial in $92 \%$ of BAVMs. Clinical presentations included hemorrhage (75\%), consciousness disturbance $(42 \%)$, seizure $(25 \%)$, neurological deficits (21\%), and headache (17\%). Interestingly, one neonatal boy presented with congestive heart 


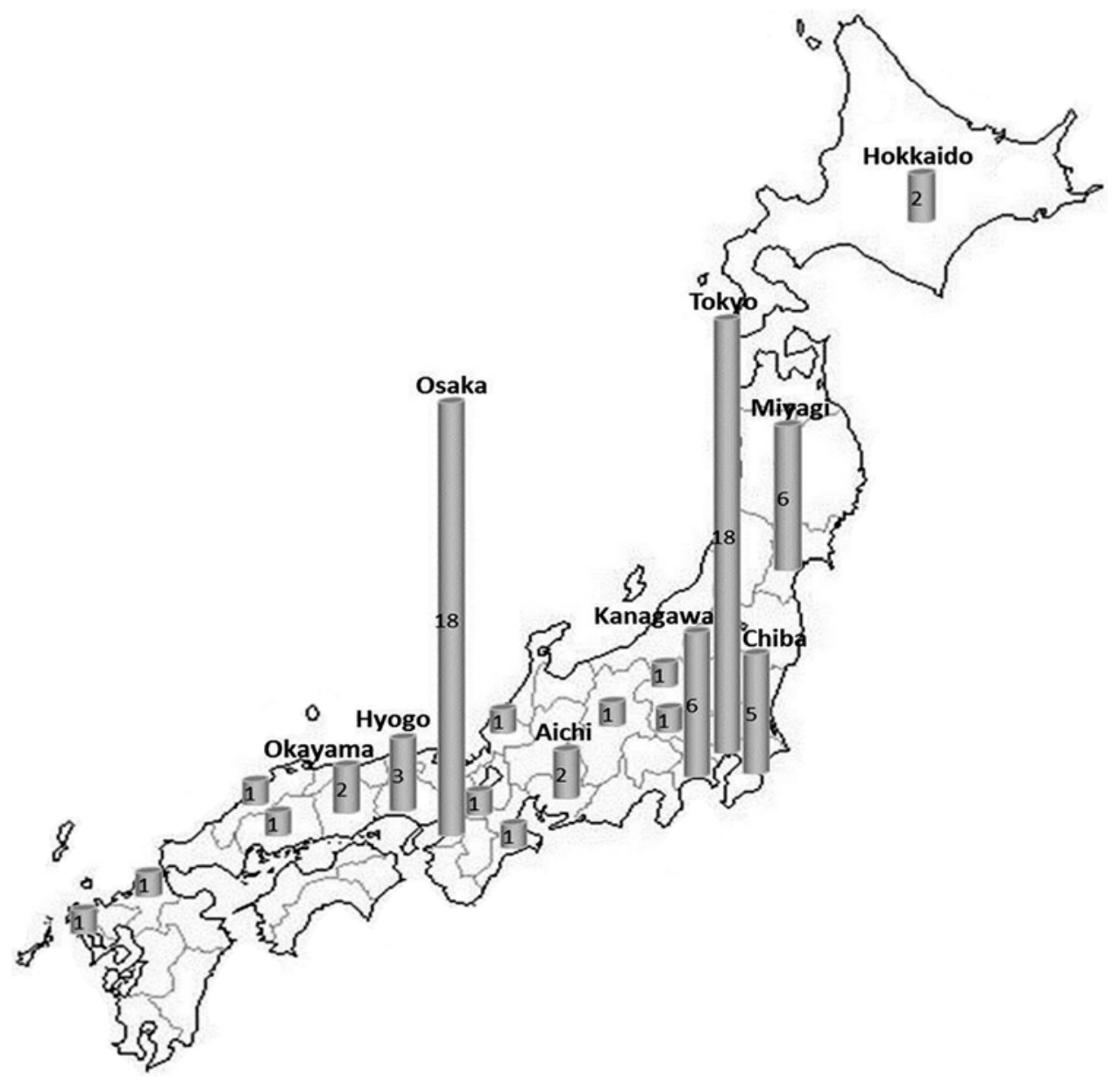

FIG. 1. Geographic distribution of 32 hospitals in Japan where pediatric patients with intracranial AV shunts were ultimately treated. The height of each column indicates the number of patients in the given prefecture.

failure. Surgical treatments were performed in $42 \%$ of BAVM patients and endovascular treatments in $42 \%$. Stereotactic radiosurgery was performed in 7 children $(29 \%)$ 4 or 5 years old. A favorable outcome was observed in $83 \%$ of BAVM patients. The mortality rate was $0 \%$.

\section{PAVFs}

Twenty-two patients developed PAVFs, and 12 of them (55\%) were neonates (Table 5). One fetal death occurred due to PAVF. Males were dominant $(68 \%)$ in this lesion group. The most common lesion location was supratentorial (68\%), and two PAVFs were located in the galenic cistern. Clinical presentation included hydrovenous disorder (hydrocephalus, macrocrania, and ventriculomegaly; $50 \%$ ), hemorrhage $(50 \%)$, congestive heart failure $(27 \%)$, seizure (27\%), neurological deficits (27\%), and brain atrophy (18\%). Most patients (90\%) underwent endovascular treatment (19 TAEs and 1 TVE). Surgical treatment was performed for hydrovenous disorder or hemorrhage in 7 patients. Although there was no significant correlation between BNES, birth weight, or gestation period and outcome in neonatal patients $(\mathrm{r}=0.35, \mathrm{p}=0.25 ; \mathrm{r}=0.20$, $p=0.69 ; r=0.20, p=0.70$, respectively), there was a significant positive correlation between pre- and posttreat- ment BAOSs in infants and children $(r=0.720, p=0.028)$. Clinical outcomes at the last follow-up were favorable in $57 \%$ of patients and unfavorable in $43 \%$, and no deaths occurred as a result of PAVF.

\section{VGAMs}

A total of 16 patients developed VGAMs (Table 6), and $11(69 \%)$ were neonates. Three patients were infants, and two were children ( 1 and 2 years, respectively). Males were the dominant sex (81\%). The choroidal type (75\%) was the most common lesion classification. Congestive heart failure was the most common presentation (69\%), whereas hydrovenous disorder (25\%) presented in all age groups. Developmental delay was present in one infant and one child. Fourteen patients (88\%) underwent endovascular treatment (13 TAEs and 2 TVEs). In two patients, ventriculoperitoneal shunts were implanted. One neonate and one child with a poor medical status were managed conservatively. The mean BNES was 11.6, and there was no correlation between BNES, birth weight, or gestation period and outcome in neonatal patients $(\mathrm{r}=0.46, \mathrm{p}=$ $0.14 ; \mathrm{r}=0.06, \mathrm{p}=0.84 ; \mathrm{r}=0.30, \mathrm{p}=0.36$, respectively). In infants and children, there was a positive correlation between pre- and posttreatment BAOSs and outcome ( $\mathrm{r}$ 
TABLE 3. Intracranial AV shunts in patients aged 5 years or younger in the 5 years from 2012 to 2016 in Japan

\begin{tabular}{lccccc}
\hline \multicolumn{1}{c}{ Category } & BAVM & PAVF & VGAM & DAVF & Total No. (\%) \\
\hline Fetal deaths & 0 & 1 & 0 & 1 & $2(3 \%)$ \\
\hline Neonates & 1 & 12 & 11 & 6 & $30(42 \%)$ \\
\hline Infants & 1 & 3 & 3 & 3 & $10(14 \%)$ \\
\hline Children & 22 & 6 & 2 & 0 & $30(42 \%)$ \\
\hline Total no. (\%) & $24(33 \%)$ & $22(31 \%)$ & $16(22 \%)$ & $10(14 \%)$ & $72(100 \%)$ \\
\hline Annual no. & 5 & 4 & 3 & 2 & 14 \\
\hline
\end{tabular}

$=0.89, \mathrm{p}=0.04)$. Three neonates $(19 \%)$ died during the study period. Clinical outcome at the last follow-up was favorable in 50\% of all VGAM patients and $62 \%$ of the 13 surviving patients.

\section{DAVFs}

A total of 10 patients developed DAVFs (Table 7). All DAVF patients were younger than 1 year old (6 neonates, 3 infants, and 1 fetal death). Males were dominant (78\%). Lesions were located in the torcular regions in most patients (90\%), indicating that they were mostly dural sinus malformations with AV shunts. Clinical presentation was congestive heart failure (70\%), especially in neonates, hydrovenous disorder (40\%), developmental delay (30\%), hemorrhage $(20 \%)$, and brain atrophy $(20 \%)$. Eight patients $(89 \%)$ underwent endovascular treatment (8 TAEs and 2 TVEs). Ventriculoperitoneal shunts were inserted in two patients. One patient with spontaneous occlusion of a DAVF was managed conservatively. The mean BNES was 13.2. In neonates, there was no correlation between BNES, birth weight, or gestational period and outcome $(r=0.20$, $\mathrm{p}=0.69 ; \mathrm{r}=0.23, \mathrm{p}=0.65 ; \mathrm{r}=0.13, \mathrm{p}=0.80$, respectively). All three infants in this lesion group had developmental delay before treatment, and the outcome after treatment had not changed at the last follow-up. The BAOS at the last follow-up was favorable in $44 \%$ of patients and unfavorable in $55 \%$. The BAOS at the initial diagnosis in all 3 infants was less than 4 , which remained unchanged at the last follow-up.

\section{Discussion}

Clinical presentations in our series were generally similar to those reported in the literature. Around $90 \%$ of patients with PAVFs, VGAMs, and DAVFs were managed with endovascular treatment as the first-line therapy, but only $42 \%$ of those with BAVMs. This is also similar to the therapeutic approaches reported in previous studies..$^{2,16,25}$ Because pre- and posttreatment outcomes were evaluated using either BNES or BAOS in all patients, to our knowledge, this is the first report on the outcomes of a variety of intracranial AV shunts using common evaluation systems.

\section{ADRs of Pediatric Intracranial AV Shunts}

The actual ADRs of pediatric intracranial AV shunts are still unknown. Including those for intracranial AV shunts in adults, there have been no reliable ADRs thus far. ${ }^{3}$ Our study provides population-based ADRs of pe-
TABLE 4. Clinical characteristics of patients with BAVM with nidus

\begin{tabular}{|c|c|c|c|c|}
\hline Parameter & All Subjects & Neonates & Infants & Children \\
\hline No. & 24 & 1 & 1 & 22 \\
\hline Mean age & & 0 days & $1 \mathrm{mo}$ & $4 \mathrm{yrs}$ \\
\hline \multicolumn{5}{|l|}{ Sex, no. (\%) } \\
\hline M & $15(63 \%)$ & 1 & 1 & 13 \\
\hline $\mathrm{F}$ & $9(38 \%)$ & 0 & 0 & 9 \\
\hline \multicolumn{5}{|l|}{ Lesion location, no. (\%) } \\
\hline Supratentorial & $22(92 \%)$ & 0 & 1 & 21 \\
\hline Infratentorial & $2(8 \%)$ & 1 & 0 & 1 \\
\hline \multicolumn{5}{|l|}{ Presentation, no. (\%) } \\
\hline Cardiac overload & $1(4 \%)$ & 1 & 0 & 0 \\
\hline Hemorrhage & $18(75 \%)$ & 0 & 1 & 17 \\
\hline Seizure & $6(25 \%)$ & 0 & 1 & 5 \\
\hline Neurological deficit & $5(21 \%)$ & 0 & 0 & 5 \\
\hline $\begin{array}{c}\text { Consciousness } \\
\text { disturbance }\end{array}$ & $10(42 \%)$ & 0 & 0 & 10 \\
\hline Headache & $4(17 \%)$ & 0 & 0 & 4 \\
\hline Asymptomatic & $1(4 \%)$ & 0 & 0 & 1 \\
\hline \multicolumn{5}{|l|}{$\begin{array}{l}\text { BNES/BAOS at Dx, no. } \\
(\%)\end{array}$} \\
\hline$>12 / 3-5$ & $16(67 \%)$ & 1 & 1 & 14 \\
\hline $8-12 / 2$ & $2(8 \%)$ & 0 & 0 & 2 \\
\hline$<8 / 1$ & $6(25 \%)$ & 0 & 0 & 6 \\
\hline \multicolumn{5}{|l|}{ Treatment, no. (\%) } \\
\hline Surgery & $10(42 \%)$ & 0 & 1 & 9 \\
\hline Endovascular & $10(42 \%)$ & 1 & 0 & 9 \\
\hline TAE & 10 & 1 & 0 & 9 \\
\hline TVE & 0 & 0 & 0 & 0 \\
\hline Radiosurgery & $7(29 \%)$ & 0 & 0 & 7 \\
\hline Conservative & $3(13 \%)$ & 0 & 0 & 3 \\
\hline \multicolumn{5}{|l|}{ BAOS at last FU, no. (\%) } \\
\hline $3-5$ & $20(83 \%)$ & 1 & 1 & 18 \\
\hline 2 & $4(17 \%)$ & 0 & 0 & 4 \\
\hline Mean FU in mos & 30.9 & 35 & 7 & 31.9 \\
\hline
\end{tabular}

diatric intracranial AV shunts. In the literature, BAVMs, PAVFs, VGAMs, and DAVFs account for $15 \%-23 \%,{ }^{8}$ $7.3 \%-17.2 \%, 7,2530 \%-51 \%,{ }^{2}$ and $8 \%{ }^{2,16}$ of all pediatric intracranial AV shunts, respectively. In the Bicêrtre series, DAVFs numbered the fewest of the vascular malformations, showing an incidence of $8 \%$, whereas PAVFs and VGAMs each had an incidence of $41 \% .{ }^{16}$ Because these data are reported from large pediatric vascular centers with significant referral biases, no actual ADR is available to our knowledge.

Our study included 72 pediatric patients 5 years old or younger with an intracranial AV shunt during a 5-year period. This means that the ADR was 0.232 per 100,000 persons 5 years old or younger (95\% CI $0.182-0.293)$ in Japan. These 72 patients were composed of $24(33 \%)$ with BAVMs, 22 (31\%) with PAVFs, 16 (22\%) with VGAMs, and $10(14 \%)$ with DAVFs. This means that the annual number of patients with BAVMs, PAVFs, VGAMs, and 
TABLE 5. Clinical characteristics of patients with PAVF

\begin{tabular}{|c|c|c|c|c|c|}
\hline Parameter & All Subjects & Fetal Death & Neonates & Infants & Children \\
\hline No. & 22 & 1 & 12 & 3 & 6 \\
\hline Mean age & & & 6.3 days & $2.7 \mathrm{mos}$ & $2.8 \mathrm{yrs}$ \\
\hline \multicolumn{6}{|l|}{ Sex, no. $(\%)$} \\
\hline M & $15(68 \%)$ & 1 & 7 & 1 & 6 \\
\hline $\mathrm{F}$ & $7(32 \%)$ & 0 & 5 & 2 & 0 \\
\hline \multicolumn{6}{|l|}{ Lesion location, no. (\%) } \\
\hline Supratentorial & $15(68 \%)$ & 1 & 8 & 3 & 3 \\
\hline Infratentorial & $5(23 \%)$ & 0 & 2 & 0 & 3 \\
\hline Galenic cistern & $2(9 \%)$ & 0 & 2 & 0 & 0 \\
\hline \multicolumn{6}{|l|}{ Presentation, no. (\%) } \\
\hline Congestive heart failure & $6(27 \%)$ & 0 & 6 & 0 & 0 \\
\hline Hydrovenous disorder & $11(50 \%)$ & 1 & 8 & 1 & 1 \\
\hline Hemorrhage & $11(50 \%)$ & 0 & 7 & 1 & 3 \\
\hline Seizure & $6(27 \%)$ & 0 & 3 & 0 & 3 \\
\hline Neurological deficit & $6(27 \%)$ & 0 & 4 & 1 & 1 \\
\hline Brain atrophy & $4(18 \%)$ & 1 & 3 & 0 & 0 \\
\hline Developmental delay & $2(9 \%)$ & 0 & 0 & 1 & 1 \\
\hline Asymptomatic & $1(5 \%)$ & 0 & 0 & 1 & 0 \\
\hline \multicolumn{6}{|l|}{ BNES/BAOS at Dx, no. (\%) } \\
\hline$>12 / 3-5$ & $17(81 \%)$ & & 10 & 2 & 5 \\
\hline $8-12 / 2$ & $1(5 \%)$ & & 1 & 0 & 0 \\
\hline$<8 / 1$ & $3(14 \%)$ & & 1 & 1 & 1 \\
\hline \multicolumn{6}{|l|}{ Treatment, no. (\%) } \\
\hline Surgery & $7(33 \%)$ & & 4 & 1 & 2 \\
\hline Endovascular & $19(90 \%)$ & & 10 & 3 & 6 \\
\hline TAE & 19 & & 10 & 3 & 6 \\
\hline TVE & 1 & & 0 & 1 & 0 \\
\hline Radiosurgery & $1(5 \%)$ & & 0 & 0 & 1 \\
\hline Conservative & $1(5 \%)$ & & 1 & 0 & 0 \\
\hline \multicolumn{6}{|l|}{ BAOS at last FU, no. (\%) } \\
\hline $3-5$ & $12(57 \%)$ & & 5 & 2 & 5 \\
\hline 2 & $5(24 \%)$ & & 4 & 1 & 0 \\
\hline 1 & $4(19 \%)$ & & 3 & 0 & 1 \\
\hline Mean FU in mos & 29.5 & & 12 & 32.3 & 32 \\
\hline
\end{tabular}

DAVFs was roughly $5,4,3$, and 2, respectively, among 6.2 million people aged 5 or younger in Japan. Our data may be suggestive of the actual ADRs since most large hospitals in Japan, which are responsible for the management of these relatively rare diseases, were included in our study and since nearly all patients with intracranial AV shunts were likely to be referred to one of these hospitals.

\section{Postnatal Formation of Intracranial BAVMs}

Our findings and previous reports suggest that VGAMs, DAVFs (especially dural sinus malformations), and some PAVFs are formed in utero. In particular, VGAM is believed to form between the 8th and 11th week of gestation. ${ }^{21}$ In one study, VGAM and dural sinus malformations were demonstrated in fetal ultrasounds at 24-25 weeks' gestation or later..$^{13}$ On the other hand, it is still not clear when BAVMs with nidus are formed. Canonically, developmental failure in the early embryogenesis of cerebral vessels at approximately 10-14 weeks' gestation and a perpetuation of the primitive $\mathrm{AV}$ shunt are believed to be the primary causes of BAVM. ${ }^{10,19}$ Because the average age of initial presentation with BAVM is over 20-50 years of age $^{1,20,24}$ and given that BAVMs are rare in early life (age $<1$ year old), ${ }^{8}$ a growing body of evidence demonstrates the de novo formation of BAVM. ${ }^{23}$ Therefore, not all, but most BAVMs may develop much later in life..$^{12,15}$ Our data on BAVM support the hypothesis that this lesion develops later in life since we found that only one neonate and one infant had BAVM. To the contrary, neonatal and infantile presentations of VGAM, PAVF, and DAVF suggest that these AV shunts develop antenatally, which is supported by the literature., ${ }^{78,22}$

\section{Geographic Distribution of Patients}

Although it is supposed that referring local hospitals are evenly distributed, the hospitals in this study that referred patients with intracranial AV shunts were unevenly distributed geographically and were concentrated in Osaka and Tokyo, which are the two largest metropolitan areas in Japan. Because hospitals in these cities could provide multidisciplinary management consisting of the interventional neuroradiology and neurosurgery personnel as well as the 
TABLE 6. Clinical characteristics of patients with VGAM

\begin{tabular}{lcccc}
\hline \multicolumn{1}{c}{ Parameter } & All & & & \\
& Subjects & Neonates & Infants & Children \\
\hline No. & 16 & 11 & 3 & 2 \\
\hline Mean age & & 2.1 days & 5.7 mos & 1.5 yrs \\
\hline Sex, no. (\%) & & & & \\
M & $13(81 \%)$ & 8 & 3 & 2 \\
F & $3(19 \%)$ & 3 & 0 & 0 \\
\hline Lesion classification, no. (\%) & & & & \\
Choroidal type & $12(75 \%)$ & 9 & 2 & 1 \\
Mural type & $1(6 \%)$ & 1 & 0 & 0 \\
Mixed type & $3(19 \%)$ & 1 & 1 & 1 \\
\hline Presentation, no. (\%) & & & & \\
Congestive heart failure & $11(69 \%)$ & 10 & 1 & 0 \\
Hydrovenous disorder & $4(25 \%)$ & 1 & 2 & 1 \\
Hemorrhage & $1(6 \%)$ & 1 & 0 & 0 \\
Developmental delay & $2(13 \%)$ & 0 & 1 & 1 \\
\hline BNES/BAOS at Dx, no. (\%) & & & & \\
>12/3-5 & $6(38 \%)$ & 4 & 1 & 1 \\
8-12/2 & $7(44 \%)$ & 5 & 1 & 1 \\
<8/1 & $3(19 \%)$ & 2 & 1 & 0 \\
\hline Treatment, no. (\%) & & & & \\
Surgery & $2(13 \%)$ & 2 & 0 & 0 \\
Endovascular & $14(88 \%)$ & 10 & 3 & 1 \\
$\quad$ TAE & 13 & 9 & 3 & 1 \\
$\quad$ TVE & 2 & 2 & 0 & 0 \\
Radiosurgery & 0 & 0 & 0 & 0 \\
Conservative & $2(13 \%)$ & 1 & 0 & 1 \\
\hline BAOS at last FU, no. (\%) & & & & \\
3-5 & $8(50 \%)$ & 5 & 2 & 1 \\
2 & $5(31 \%)$ & 3 & 1 & 1 \\
1 & 0 & 0 & 0 & 0 \\
Mean FU in mos & $3(19 \%)$ & 3 & 0 & 0 \\
\hline & 29.6 & 30.5 & 27.7 & 27 \\
\hline
\end{tabular}

neonatology, pediatrics, obstetrics, and pediatric anesthesiology personnel, most patients were referred from local hospitals to tertiary care referral hospitals. Given difficulties in the management of pediatric vascular malformations, we recommend referring patients (including those in utero) to large, experienced pediatric vascular centers if referral is medically feasible.

\section{Clinical Presentations}

The overall spectrum of pediatric AV shunts is wide. As shown in our study, BAVMs are less common in patients aged $<1$ year, and their presentation is different from those of the other AV shunts. Contrary to BAVMs, clinical presentations with PAVFs, VGAMs, and DAVFs depend on the age of presentation. $2,7,11,16,18,22,25$ Despite the different angioarchitectures, PAVFs, VGAMs, and DAVFs present with congestive heart failure in neonates and with hydrovenous disorder (hydrocephalus, macrocrania, and ventriculomegaly) in infancy. In childhood, they present with seizures, developmental delays, focal neurological deficits, and hemorrhage.

In our study, neonates with VGAMs and DAVFs com-
TABLE 7. Clinical characteristics of patients with DAVF

\begin{tabular}{|c|c|c|c|c|}
\hline Parameter & $\begin{array}{c}\text { All } \\
\text { Subjects }\end{array}$ & $\begin{array}{l}\text { Fetal } \\
\text { Death }\end{array}$ & Neonates & Infants \\
\hline No. & 10 & 1 & 6 & 3 \\
\hline Mean age & & & 0 day & $3 \mathrm{mos}$ \\
\hline \multicolumn{5}{|l|}{ Sex, no. $(\%)$} \\
\hline M & $7(78 \%)$ & 0 & 5 & 2 \\
\hline $\mathrm{F}$ & $2(22 \%)$ & 0 & 1 & 1 \\
\hline Unidentified & 1 & 1 & 0 & 0 \\
\hline \multicolumn{5}{|l|}{ Lesion location, no. (\%) } \\
\hline Torcular & $9(90 \%)$ & 1 & 6 & 2 \\
\hline Other & $1(10 \%)$ & 0 & 0 & 1 \\
\hline \multicolumn{5}{|l|}{ Presentation, no. (\%) } \\
\hline Congestive heart failure & $7(70 \%)$ & 1 & 5 & 1 \\
\hline Hydrovenous disorder & $4(40 \%)$ & 0 & 2 & 2 \\
\hline Hemorrhage & $2(20 \%)$ & 0 & 1 & 1 \\
\hline Developmental delay & $4(40 \%)$ & 0 & 1 & 3 \\
\hline Brain atrophy & $2(20 \%)$ & 0 & 0 & 2 \\
\hline Neurological deficit & $1(10 \%)$ & 0 & 0 & 1 \\
\hline Proptosis & $1(10 \%)$ & 0 & 0 & 1 \\
\hline \multicolumn{5}{|l|}{ BNES/BAOS at Dx, no. (\%) } \\
\hline$>12 / 3-5$ & $3(33 \%)$ & & 3 & 0 \\
\hline $8-12 / 2$ & $5(56 \%)$ & & 3 & 2 \\
\hline$<8 / 1$ & $1(11 \%)$ & & 0 & 1 \\
\hline \multicolumn{5}{|l|}{ Treatment, no. (\%) } \\
\hline Surgery & $2(22 \%)$ & & 2 & 0 \\
\hline Endovascular treatment & $8(89 \%)$ & & 5 & 3 \\
\hline TAE & 8 & & 5 & 3 \\
\hline TVE & 2 & & 2 & 0 \\
\hline Radiosurgery & 0 & & 0 & 0 \\
\hline Conservative & $1(11 \%)$ & & 1 & 0 \\
\hline \multicolumn{5}{|l|}{ BAOS at last FU, no. (\%) } \\
\hline $3-5$ & $4(44 \%)$ & & 4 & 0 \\
\hline 2 & $3(33 \%)$ & & 1 & 2 \\
\hline 1 & $2(22 \%)$ & & 1 & 1 \\
\hline Mean FU in mos & 32.7 & & 32.7 & 32.7 \\
\hline
\end{tabular}

monly presented with congestive heart failure, and infants with these lesions commonly developed hydrovenous disorder. Neonates with PAVFs presented with hydrovenous disorder and hemorrhage as well as congestive heart failure. Children (age $>1$ year old) with PAVFs and BAVMs presented with hemorrhage, focal neurological deficits, consciousness disturbances, and seizures. As is widely reported, 2,7,16,18,25 males were dominant in all types of AV shunts (overall male ratio: 70\%), especially in VGAMs (81\%) and DAVFs (78\%) in our study.

\section{Treatment and Outcome}

\section{BAVMs}

It is controversial and unclear whether pediatric BAVMs have a greater risk ${ }^{14}$ or the same risk ${ }^{5,6}$ of hemorrhage as adult BAVMs. No ADR data focusing on BAVMs in patients younger than 5 years are available. In the literature, $60 \%-66 \%$ of patients with BAVMs aged 18 years or younger were treated with surgery, whereas $48 \%-70 \%$ underwent endovascular treatments and $26 \%-70 \%$ were 
treated with stereotactic radiosurgery as single or multiple modalities., ${ }^{4,5}$ Stereotactic radiosurgery could be used to treat patients more than 2 years of age. ${ }^{9}$ In our series, $42 \%$ of patients with BAVMs were treated surgically or endovascularly, whereas stereotactic radiosurgery was performed in 7 patients (29\%) aged 4 or 5 years old. Outcome in the literature was favorable in $76.4 \%-81 \%$ of patients and poor in $19 \%$ of patients, including death in 4.7\%-6.5\% ${ }^{4,8}$ Although the outcome of most patients in our series was favorable at the last follow-up (83\%) and similar to the reported rates, the relative success in eliminating lesions was not clear. A longer follow-up is needed to judge long-term safety and efficacy of these treatments including stereotactic radiosurgery.

\section{PAVFs}

In a prior study of 147 patients with PAVFs who were 18 or younger, $83.7 \%$ of patients were treated with embolization and $17 \%$ with surgery. ${ }^{18}$ Nineteen of 23 patients in that study were treated with surgical intervention prior to 2002, when endovascular treatment was less popular. In the past two decades, remarkable advances in endovascular treatment have made this modality the treatment of choice for PAVFs. In that prior study, overall outcome was favorable in $81.6 \%$ and unfavorable in $18.5 \%$, including a mortality rate of $8.5 \% .^{18}$ In our study, $90 \%$ of patients underwent endovascular treatment as a first-line therapy (19 TAEs and 1 TVE), and overall outcome was favorable in $57 \%$ and unfavorable in $43 \%$ with a mortality rate of $0 \%$. Outcome may be less favorable than in previous reports because of selection bias and/or a high percentage of neonates in our study (55\% of PAVFs).

\section{VGAMs}

In a large study of 216 patients with VGAMs, Lasjaunias et al. ${ }^{16}$ reported an overall mortality of $10.6 \%, 143$ (74\%) of 193 surviving patients with a favorable outcome, and 50 patients $(26 \%)$ with an unfavorable outcome after endovascular treatment. In a systematic review of 34 studies, 667 patients underwent embolization, ${ }^{26}$ and outcome was favorable in $68 \%$ and unfavorable (including death) in $31 \%$, with a mortality rate of $16 \%$. In our series, 14 patients $(88 \%)$ underwent endovascular treatment, $13 \%$ were managed conservatively, and $13 \%$ were surgically treated. Outcome for the 13 surviving patients was favorable in $62 \%$ and unfavorable in $38 \%$, and mortality was $19 \%$, a rate somewhat inferior to those in previous reports. ${ }^{17,26}$ This may have been due to selection bias and/or a high percentage of neonates in our study (69\% of VGAMs).

\section{DAVFs}

Pediatric DAVFs are classified into three groups: dural sinus malformation with AV shunts, infantile type, and adult type.$^{16}$ Dural sinus malformations with AV shunts are common in antenatal and perinatal periods. A 1996 study of 29 patients with DAVFs reported a mortality rate of $31 \%$, a favorable outcome in $45 \%$ of patients, and an unfavorable outcome in $24 \%$ of patients. ${ }^{16}$ In a study by the same author group, among the 30 patients with dural sinus malformation with $\mathrm{AV}$ shunts (age $<2$ years old), ${ }^{2}$ 16 patients underwent endovascular treatment with a $75 \%$ favorable outcome, and 14 patients were managed conservatively. Among this latter group managed conservatively, outcome was favorable in 59\% and unfavorable in $41 \%$ including a mortality of $38 \%$.

Torcular dural sinus malformations have been reported as "isolated in utero dural sinus thrombosis" (prenatal group) in the obstetric and/or fetal imaging literature and as "dural sinus malformation with AV shunts" (postnatal group) in the neurosurgical and/or neurointerventional literature. It has recently been recognized that the two groups share a common etiology and an evolutional continuum. ${ }^{27}$ Although the prenatal group had an $83 \%$ survival rate and a $62 \%$ favorable outcome rate, the postnatal group had a $59 \%$ survival rate and only a $29 \%$ favorable outcome rate due to different clinical courses. Because most DAVFs in our study were presumed to be dural sinus malformations with AV shunts and because obstetricians did not directly participate in this study, many patients in our series belonged to the postnatal group with an unfavorable outcome. In fact, all patients except for one neonate with spontaneous regression required endovascular treatment, and outcome was favorable in $45 \%$ and unfavorable in $55 \%$. Although the mortality was $0 \%$, outcome was generally similar to those in previous reports.

\section{Study Limitations}

This study may have the following limitations. It is a retrospective study of intracranial AV shunts in the recent 5 -year period. Because participation was voluntary, some patients may have gone unreported. Although all major large neurosurgical hospitals and children's hospitals in Japan participated in the study, not all eligible patients may be included. Patients who died in utero or perinatally and neonates who were not diagnosed adequately or who were initially treated by neonatologists and died soon thereafter were not reported. However, considering the extensive coverage of hospitals normally involved in the treatment of pediatric intracranial AV shunts in Japan, our study provided significant data on the characteristics, especially ADRs, of these rare intracranial AV shunts.

\section{Conclusions}

Our nationwide study showed that the ADRs of BAVM, PAVF, VGAM, and DAVF in patients 5 years old or younger were $0.0775,0.0710,0.0517$, and 0.0323 per 100,000 persons, respectively. In neonates and infants younger than 1 year, VGAM, DAVF, and PAVF were relatively common; however, BAVMs were extremely rare, which supports the idea that a majority of BAVMs are formed postnatally, as opposed to an embryonic formation and delayed symptomatic manifestation later in life.

\section{Acknowledgments}

We thank all members of the Japanese Society for Neuroendovascular Therapy and the Japanese Society for Pediatric Neurosurgery who joined and supported this study.

\section{References}

1. Al-Shahi R, Bhattacharya JJ, Currie DG, Papanastassiou V, 
Ritchie V, Roberts RC, et al: Prospective, population-based detection of intracranial vascular malformations in adults: the Scottish Intracranial Vascular Malformation Study (SIVMS). Stroke 34:1163-1169, 2003

2. Barbosa M, Mahadevan J, Weon YC, Yoshida Y, Ozanne A, Rodesch G, et al: Dural sinus malformations (DSM) with giant lakes, in neonates and infants review of 30 consecutive cases. Interv Neuroradiol 9:407-424, 2003

3. Berman MF, Sciacca RR, Pile-Spellman J, Stapf C, Connolly ES Jr, Mohr JP, et al: The epidemiology of brain arteriovenous malformations. Neurosurgery 47:389-397, 2000

4. Blauwblomme T, Bourgeois M, Meyer P, Puget S, Di Rocco F, Boddaert N, et al: Long-term outcome of 106 consecutive pediatric ruptured brain arteriovenous malformations after combined treatment. Stroke 45:1664-1671, 2014

5. Darsaut TE, Guzman R, Marcellus ML, Edwards MS, Tian L, Do HM, et al: Management of pediatric intracranial arteriovenous malformations: experience with multimodality therapy. Neurosurgery 69:540-556, 2011

6. Fullerton HJ, Achrol AS, Johnston SC, McCulloch CE, Higashida RT, Lawton MT, et al: Long-term hemorrhage risk in children versus adults with brain arteriovenous malformations. Stroke 36:2099-2104, 2005

7. Hetts SW, Keenan K, Fullerton HJ, Young WL, English JD, Gupta N, et al: Pediatric intracranial nongalenic pial arteriovenous fistulas: clinical features, angioarchitecture, and outcomes. AJNR Am J Neuroradiol 33:1710-1719, 2012

8. Hladky JP, Lejeune JP, Blond S, Pruvo JP, Dhellemmes P: Cerebral arteriovenous malformations in children: report on 62 cases. Childs Nerv Syst 10:328-333, 1994

9. Kano H, Kondziolka D, Flickinger JC, Yang HC, Flannery TJ, Awan NR, et al: Stereotactic radiosurgery for arteriovenous malformations, part 2: management of pediatric patients. J Neurosurg Pediatr 9:1-10, 2012

10. Kaplan HA, Aronson SM, Browder EJ: Vascular malformations of the brain. An anatomical study. J Neurosurg 18:630-635, 1961

11. Kincaid PK, Duckwiler GR, Gobin YP, Viñuela F: Dural arteriovenous fistula in children: endovascular treatment and outcomes in seven cases. AJNR Am J Neuroradiol 22:1217-1225, 2001

12. Komiyama M: Pathogenesis of brain arteriovenous malformations. Neurol Med Chir (Tokyo) 56:317-325, 2016

13. Komiyama M, Ishiguro T, Kitano S, Sakamoto H, Nakamura $\mathrm{H}$ : Serial antenatal sonographic observation of cerebral dural sinus malformation. AJNR Am J Neuroradiol 25:14461448,2004

14. Kondziolka D, Humphreys RP, Hoffman HJ, Hendrick EB, Drake JM: Arteriovenous malformations of the brain in children: a forty year experience. Can J Neurol Sci 19:40-45, 1992

15. Lasjaunias P: A revised concept of the congenital nature of cerebral arteriovenous malformations. Interv Neuroradiol 3:275-281, 1997

16. Lasjaunias P, Magufis G, Goulao A, Piske R, Suthipongchai S, Rodesch R, et al: Anatomoclinical aspects of dural arteriovenous shunts in children. Review of 29 cases. Interv Neuroradiol 2:179-191, 1996

17. Lasjaunias PL, Chng SM, Sachet M, Alvarez H, Rodesch G, Garcia-Monaco R: The management of vein of Galen aneurysmal malformations. Neurosurgery 59 (5 Suppl 3):S184S194, S3-S13, 2006

18. Madsen PJ, Lang SS, Pisapia JM, Storm PB, Hurst RW, Heuer GG: An institutional series and literature review of pial arteriovenous fistulas in the pediatric population: clinical article. J Neurosurg Pediatr 12:344-350, 2013

19. Mullan S, Mojtahedi S, Johnson DL, Macdonald RL: Embryological basis of some aspects of cerebral vascular fistulas and malformations. J Neurosurg 85:1-8, 1996
20. Perret G, Nishioka H: Report on the cooperative study of intracranial aneurysms and subarachnoid hemorrhage. Section VI. Arteriovenous malformations. An analysis of 545 cases of cranio-cerebral arteriovenous malformations and fistulae reported to the cooperative study. J Neurosurg 25:467-490, 1966

21. Raybaud CA, Strother CM, Hald JK: Aneurysms of the vein of Galen: embryonic considerations and anatomical features relating to the pathogenesis of the malformation. Neuroradiology 31:109-128, 1989

22. Roccatagliata L, Bracard S, Holmin S, Soderman M, Rodesch G: Pediatric intracranial arteriovenous shunts: a global overview. Childs Nerv Syst 29:907-919, 2013

23. Shimoda Y, Osanai T, Nakayama N, Ushikoshi S, Hokari M, Shichinohe $\mathrm{H}$, et al: De novo arteriovenous malformation in a patient with hereditary hemorrhagic telangiectasia. J Neurosurg Pediatr 17:330-335, 2016

24. Stapf C, Mast H, Sciacca RR, Berenstein A, Nelson PK, Gobin YP, et al: The New York Islands AVM Study: design, study progress, and initial results. Stroke 34:e29-e33, 2003

25. Weon YC, Yoshida Y, Sachet M, Mahadevan J, Alvarez H, Rodesch G, et al: Supratentorial cerebral arteriovenous fistulas (AVFs) in children: review of 41 cases with 63 non choroidal single-hole AVFs. Acta Neurochir (Wien) 147:17-31, 2005

26. Yan J, Wen J, Gopaul R, Zhang CY, Xiao SW: Outcome and complications of endovascular embolization for vein of Galen malformations: a systematic review and meta-analysis. J Neurosurg 123:872-890, 2015

27. Yang E, Storey A, Olson HE, Soul J, Estroff JA, Trenor CC, et al: Imaging features and prognostic factors in fetal and postnatal torcular dural sinus malformations, part II: synthesis of the literature and patient management. J Neurointerv Surg 10:471-475, 2018

\section{Disclosures}

The authors report no conflict of interest concerning the materials or methods used in this study or the findings specified in this paper.

\section{Author Contributions}

Conception and design: Komiyama, Niimi, Oishi. Acquisition of data: Komiyama, Terada, Ishiguro. Analysis and interpretation of data: Komiyama, Ishiguro, Niimi, Oishi. Drafting the article: Terada. Critically revising the article: Komiyama, Terada, Ishiguro. Reviewed submitted version of manuscript: all authors. Approved the final version of the manuscript on behalf of all authors: Komiyama. Statistical analysis: Komiyama, Terada. Administrative/technical/material support: Komiyama, Niimi, Oishi.

\section{Supplemental Information Previous Presentations}

Portions of this work were presented in abstract form at the 33th Annual Meeting of the Japanese Society for Neuroendovascular Therapy, Tokyo, Japan, November 23, 2017, at the 13th Meeting of the Asian-Australasian Federation of Interventional and Therapeutic Neuroradiology, Kota Kinabalu Sabah, Malaysia, March 9, 2018, and at the 47th meeting of Japanese Society on Surgery for Cerebral Stroke, Fukuoka, Japan, March 17, 2018.

\section{Correspondence}

Masaki Komiyama: Osaka City General Hospital, Osaka, Japan. komiyama@japan-mail.com. 